\title{
Workforce demand for neurosurgeons in the United States of America: a 13-year retrospective study
}

\author{
Daniel L. Friedlich, A.B., Paul J. Feustel, Ph.D., and A. John Popp, M.D. \\ Division of Neurosurgery, Department of Surgery, Albany Medical Center, Albany, New York
}

Object. The workforce demand for neurosurgeons was quantified by a review and an analysis of journal recruitment advertisements published over the past 13 years.

Methods. A retrospective analysis of recruitment advertisements from July 1985 through June 1998 was performed by examining issues of the Journal of Neurosurgery and Neurosurgery. Advertisement information that appeared in each journal during the last 3 years was collected from alternating months (July to May); information that appeared prior to that time was collected from alternating recruitment years back to 1985 . The authors examined the following workforce parameters: practice venue, subspecialization, and practice size.

They found no significant decrease in neurosurgical recruitment advertisements. There was an average of $102.7 \pm 22.4$ (standard deviation) advertised positions per year during the most recent 3 years compared with $92.6 \pm 17.9$ advertised positions per year during the preceding decade. Similarly, there has been no decline in advertised positions either in academic $(33 \pm 6.1$ year for the most recent 3 years compared with $32.8 \pm 5.9 /$ year for $1985-1995)$ or private practice $(69.7 \pm 21.6 /$ year for the most recent 3 years compared with $59.8 \pm 13.4 /$ year for 1985-1995). A shift in demand toward subspecialty neurosurgery was observed. During the past 3 years, $31.2 \pm 5.9 \%$ of advertised positions called for subspecialty expertise, compared with $18.5 \pm 2.8 \%$ for the preceding decade $(\mathrm{p}<0.05)$. The largest number of subspecialty advertisements designated positions for spine and pediatric neurosurgeons. Private practice advertisements increasingly sought to add neurosurgeons to group practices.

Conclusions. Contrary to previous reports and a prevailing myth, our data show no decrease in workforce demand for neurosurgeons in the United States over the past 3 years compared with the prior decade. A shift toward subspecialist recruitment, particularly for spine neurosurgeons, has been demonstrated in both academic and private practice venues.

Key Words * employment * health workforce * medical economics * neurosurgery * subspecialty fellowship training program

Physician workforce size has been a periodic topic of discussion since the issuance of the Flexner report[6] in 1910. During the ensuing eight decades, the intensity of the workforce debate has fluctuated from quiescent to heated, with the latter state currently prevailing. Physician workforce size is not only 
an economic concern, but represents a fundamental driving force that affects most aspects of medical care delivery.

Although the number of neurosurgeons practicing in the United States represents less than $1 \%$ of all practicing physicians, the workforce size of this specialty has not escaped the scrutiny of the medical policy pundits. $[18,19]$ In fact, neurosurgery has often been cited as an example of an overpopulated specialty. $[8,16,17,20]$ Although the assertion that there are too many neurosurgeons has its proponents, many recognize that workforce needs are complex and have far-reaching implications that require analyses that go beyond simple estimates of workforce size. $[5,11,13]$

In the present study we reviewed advertisements for positions available in the specialty of neurosurgery over the past 13 years to assess trends in the demand for clinically active neurosurgeons.

\section{MATERIALS AND METHODS}

Advertisements for available neurosurgical positions were collected from the Journal of Neurosurgery and Neurosurgery. Representatives from these journals (personal communications, 1997) denied any significant change in journal policy concerning advertisement sales or methods of acquiring recruitment advertisements during the study period.

Because recruitment for neurosurgical residents anticipating completion of training begins in July, peaks in November, and continues until May, we designated this time period as one "recruitment year."

Because most advertisements appear in journals for longer than 1 month, we surveyed advertisements from alternating months during this period (July-May). We collected advertisement information annually for the past 3 recruitment years; for the years prior to that, we examined alternate recruitment years back to 1985 . We, therefore, studied the recruitment years 1985-1986, 1987-1988, 1989-1990, 1991-1992, 1993-1994, 1995-1996, 1996-1997, and 1997-1998 during the months of July, September, November, January, March, and May.

Each advertisement was eligible for inclusion only once. Advertisements were allocated to the monthly issue in which they were first observed; advertisements that appeared in successive monthly issues in the same journal or that appeared in both journals were not recorded more than once. If an advertisement specified two or more available positions, each was recorded as an individual position. Fellowships, military positions, nonsurgical research positions, and foreign opportunities were excluded.

Recruitment advertisements were divided on the basis of whether they represented an academic or private practice venue. An academic employment opportunity was defined as an advertisement by an institution with an Accreditation Council for Graduate Medical Education-approved neurosurgery residency training program. All others were categorized as private practice.

If the terms "fellowship training required" or "necessary experience" were present when defining a desired subspecialty, such as spine or pediatrics, the advertisement was recorded as requiring a subspecialist (specialty neurosurgeon). An advertisement was designated as generalist (general neurosurgeon) if there was no information concerning subspecialty-specific experience or training. The terms "preferred experience in" or "interests in" a subspecialty were not considered sufficiently strong terms to warrant inclusion as a subspecialist position, because it is possible that a neurosurgeon without subspecialist experience or interest might ultimately occupy the position. In addition, in cases in which advertisements listed a single position available with several acceptable possibilities of subspecialty expertise, the appropriate fractional designation was made. For example, a recruitment advertisement for 
one academic neurosurgeon with necessary training in skull base, vascular, or spine neurosurgery was allocated as one third of a position per subspecialty.

Private practice advertisements were divided into solo, solo plus, or group practice. The "solo" category represented the demand for one neurosurgeon to work in the absence of another neurosurgeon. Solo advertisements announced the desire to develop a new practice in a hospital or to sell a singly operated practice. The term "solo plus" was used to identify the presence of one neurosurgeon with intent to expand by hiring an additional neurosurgeon. "Group" practice represented two or more neurosurgeons with intent to expand their practice by at least one neurosurgeon.

\section{Statistical Analysis}

Values are expressed as the mean \pm standard deviation. Differences between the past 3 years and the preceding decade were assessed using the nonparametric Mann-Whitney U-test with significance accepted at a probability level lower than 0.05 . All analyses were performed using statistical computer software (Statistica, version 5.0; Statsoft, Tulsa, OK).

\section{RESULTS}

\section{All Neurosurgeons}

The average number of neurosurgical recruitment advertisements encountered in Neurosurgery and the Journal of Neurosurgery was $96.4 \pm 22.4$ per year. This number did not decrease over the study period (Fig. 1). There were $102.7 \pm 17.9$ advertised positions per year during the most recent 3 years compared with $92.6 \pm 17.9$ advertised positions per year during the preceding decade (not significant; $\mathrm{p}=0.88$ ).

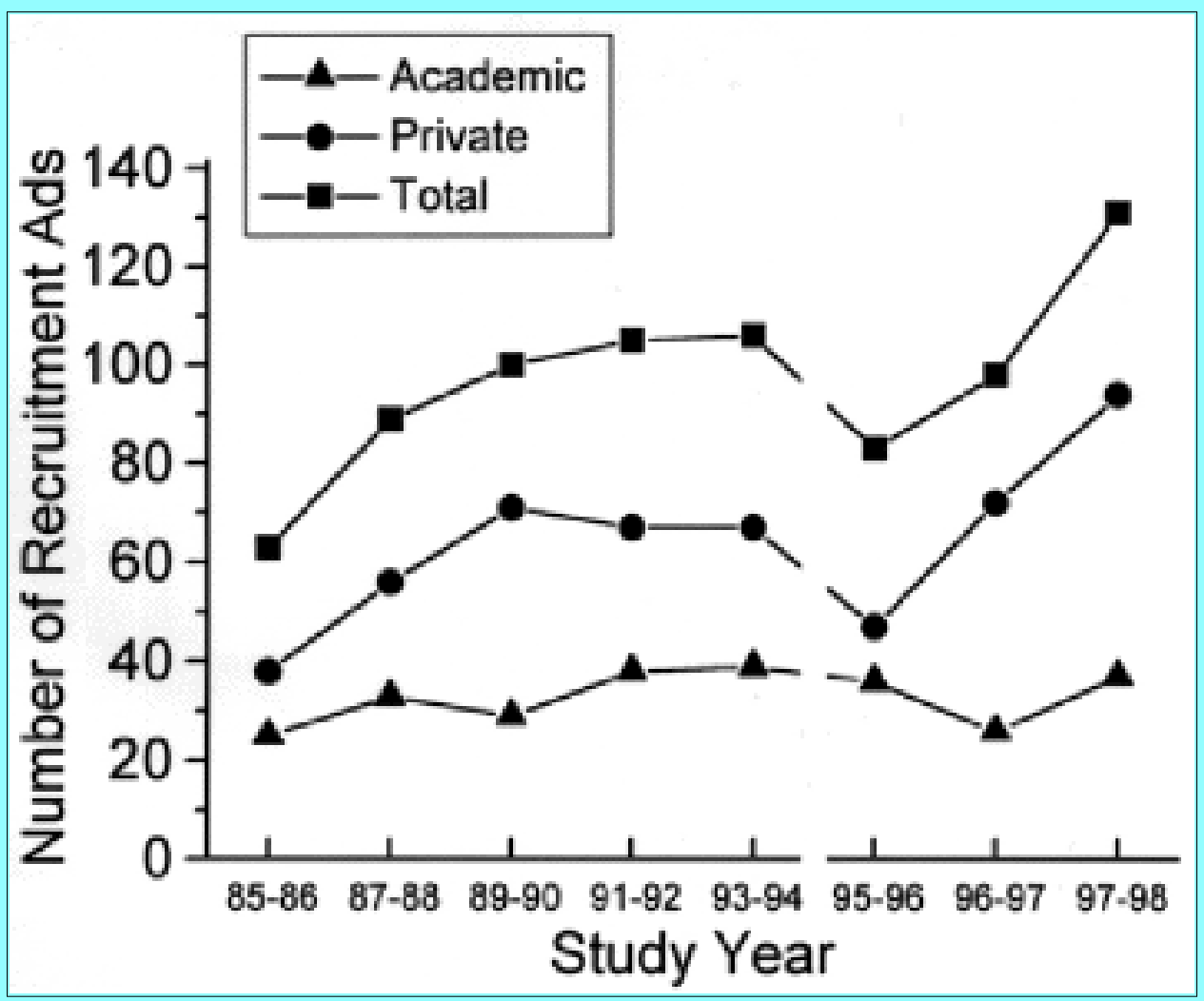

Fig. 1. Graph showing that there has been no decrease in the demand for neurosurgeons, as estimated from advertised positions, from 1985 to the present. Academic practice, private practice, and total combined advertised positions demonstrate an upward trend with a 
transient decline seen during 1995 and 1996.

There has been an increase in the percentage of advertisements for subspecialists as opposed to generalists during the study period (Fig. 2). In 1985-1986, there was a low of 14\% of advertisements seeking subspecialists, whereas in 1997-1998, there was a high of 35\% for subspecialists. Over the last 3 years $31.2 \pm 5.9 \%$ of advertisements sought candidates in subspecialty areas of neurosurgery, which was significantly more than the $18.5 \pm 2.8 \%$ for the preceding decade $(\mathrm{p}<0.05)$. Of the subspecialties in which there were more than five total positions advertised throughout the 13 years, $13.9 \pm 2.6$ advertisements per year stipulated spine subspecialization during the past 3 years, which was significantly greater than the $3.6 \pm 3.2$ advertisements per year during the preceding decade $(p<0.05)$. A similar trend in pediatric neurosurgery-- $8.3 \pm 3.2$ per year during the past 3 years compared with $3.7 \pm$ 2.3 per year during the preceding decade--did not achieve statistical significance $(p=0.07)$.

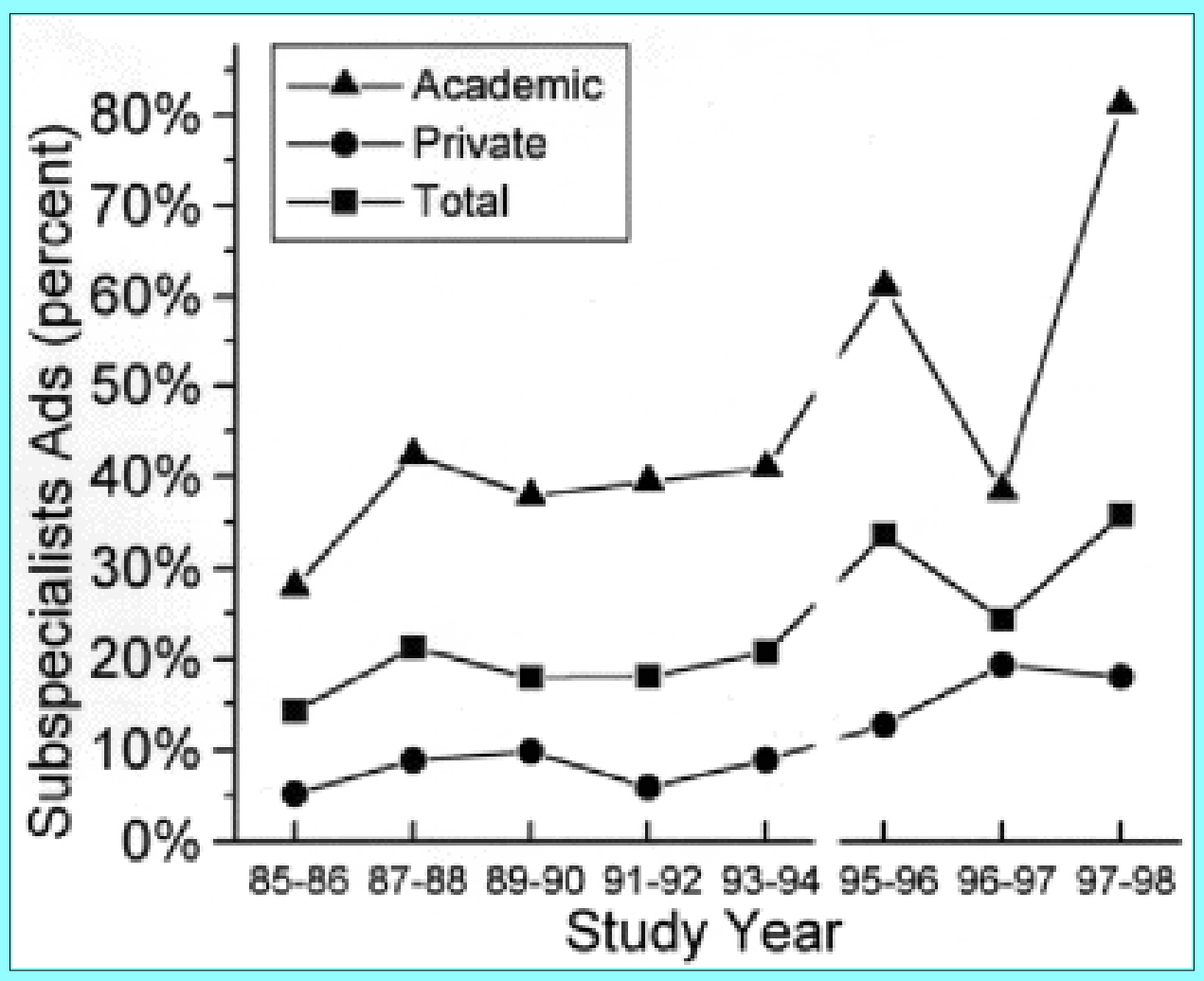

Fig. 2. Graph showing that there has been a significant increase in the percentage of advertisements for neurosurgical subspecialists. The ordinates show the percentage of total advertisements in each category (academic, private, or total) calling for subspecialization.

\section{Academic Practice}

The number of advertised academic positions averaged $32.7 \pm 5.4$ per year since 1985 . There was no decline in positions advertised in the most recent 3 years ( $33 \pm 6.1$ /year) compared with the preceding decade $(32.8 \pm 5.9$ /year). There appeared to be an increase in the percentage of subspecialist advertisements over the study period (Fig. 2); however, there was no statistical difference in the $60.2 \pm$ $21.3 \%$ subspecialist advertisements for the last 3 years compared with $37.4 \pm 5.6 \%$ in the preceding decade ( $\mathrm{p}=0.10)$. Of the available academic positions, the subspecialties of spinal and pediatric neurosurgery appeared to show increases in demand (Table 1), but neither increase was statistically significant. 
TABLE 1

SUMMARY OF SUBSPECIALTY ADVERTISEMENTS

\begin{tabular}{|c|c|c|c|c|c|c|c|c|}
\hline Recruitment Category & $85-86$ & $87-88$ & $89-90$ & $91-92$ & $93-94$ & $95-96$ & $96-97$ & $97-98$ \\
\hline $\begin{array}{l}\text { academic practice } \\
\text { general } \\
\text { subspecialties }\end{array}$ & 14 & 18 & 16 & 21 & 21 & 12 & 16 & 7 \\
\hline cranial base & 0 & 0 & 0 & 0 & 1.3 & 0.5 & 0 & 1 \\
\hline epilepsy & 1.5 & 0.6 & 1 & 1.3 & 0.8 & 1 & 1 & 0 \\
\hline functional & 0 & 0 & 0 & 0 & 0 & 1 & 0.3 & 2.5 \\
\hline oncology & 1 & 3.8 & 1.3 & 3 & 1.3 & 0 & 1 & 2.3 \\
\hline pain & 1 & 0.5 & 0.3 & 0 & 0 & 0 & 0.3 & 1 \\
\hline pediatrics & 1 & 4 & 1 & 3.6 & 4 & 5 & 3 & 9 \\
\hline spine & 0 & 1.1 & 3.5 & 1.6 & 5.3 & 9 & 3 & 9.3 \\
\hline stereo tactic & 1.5 & 1.1 & 1.3 & 1.3 & 0.8 & 1 & 0.3 & 1.5 \\
\hline trauma & 0 & 1 & 1.5 & 1 & 0.5 & 3 & 1 & 3 \\
\hline vascular & 1 & 1.6 & 1 & 2 & 1.8 & 1.5 & 0 & 0.3 \\
\hline total & 7 & 14 & 11 & 14 & 16 & 22 & 10 & 30 \\
\hline not specified & 4 & 1 & 2 & 2 & 2 & 2 & 0 & 0 \\
\hline $\begin{array}{l}\text { private practoce } \\
\text { general }\end{array}$ & 34 & 49 & 64 & 63 & 61 & 41 & 54 & 62 \\
\hline subspecialty & & & & & & & & \\
\hline cranial base & 0 & 0 & 0 & 0 & 0 & 0 & 1 & 0.5 \\
\hline epilepsy & 0 & 1 & 0 & 0.2 & 0 & 0 & 0 & 0 \\
\hline functional & 0 & 0 & 0 & 0 & 0 & 0 & 0 & 1 \\
\hline microsurgery & 2 & 2 & 0 & 0 & 0 & 0 & 0 & 0 \\
\hline oncology & $\overline{0}$ & $\overline{0}$ & 2 & 0 & 0 & 0 & 0 & 0 \\
\hline pediatrics & 0 & 0 & 1 & 1 & 3 & 2 & 3 & 3 \\
\hline spine & 0 & 0.5 & 1 & 2.2 & 3 & 4 & 9 & 7.5 \\
\hline stereo tactic & 0 & 0.5 & 0 & 0.2 & 0 & 0 & 0 & 1 \\
\hline trauma & 0 & 0 & 2 & 0.4 & 0 & 0 & 0 & 0 \\
\hline vascular & 0 & 1 & 1 & 0 & 0 & 0 & 1 & 2 \\
\hline total & 2 & 5 & 7 & 4 & 6 & 6 & 14 & 15 \\
\hline not specified & 2 & 2 & 0 & 0 & 0 & 0 & 4 & 13 \\
\hline
\end{tabular}

\section{Private Practice}

The number of advertised private practice positions averaged $63.5 \pm 16.2$ per year since 1985 , approximately twice the number of academic positions. There has been no decline in positions advertised with $69.7 \pm 21.6$ per year for the most recent 3 years compared with $59.8 \pm 13.4$ per year for the preceding decade. There was an upward trend in the number of advertised positions for both generalist and subspecialist. The percentage of advertisements for subspecialists in private practice increased from a minimum of 5\% in 1985-1986 to a maximum of 19\% in 1997-1998 (Fig. 2). This reflects a significant increase in the percentage of subspecialist advertisements: $16.3 \pm 3.4 \%$ of advertisements during the last 3 years compared with $7.8 \pm 2 \%$ during the preceding decade $(\mathrm{p}<0.05)$. These percentages are below the percentage of subspecialists sought by academic institutions. Of the subspecialties, $6.8 \pm 2.6$ advertisements per year were directed toward spine neurosurgeons during the past 3 years, which was significantly greater than the $1.3 \pm 1.2$ advertisements per year during the preceding decade $(\mathrm{p}<0.05)$.

For the entire study period, the percentages of private practice positions advertised for solo, solo plus, and group practice were $10 \pm 3 \%, 17 \pm 5 \%$, and $51 \pm 12 \%$, respectively. For the past 3 years and the preceding decade, respectively, there were $7 \pm 4$ and $7 \pm 3$ advertisements per year for solo practice, $11 \pm$ 1 and $10 \pm 3$ advertisements per year for solo plus practice, and $41 \pm 6$ and $28 \pm 10$ advertisements per year for group practice (approximately 15 advertisements/year did not note practice size). The strong 
trend for the number of group practice advertisements to increase did not quite achieve statistical significance $(\mathrm{p}=0.053)$.

\section{DISCUSSION}

In contrast to predictions that specialty medical practice and, particularly, neurosurgical practice opportunities might decelerate with the growth of managed care, we found continued and, perhaps, increasing demand for neurosurgeons during the 1997-1998 recruitment year, which demonstrated the greatest number of recruitment advertisements. In addition, we observed a significant increase in employment opportunities for subspecialty expertise in neurosurgery, in general, with a specific increase in the number of advertisements directed toward spinal neurosurgeons--a subspecialty job opportunity that was not advertised until the 1989-1990 recruitment year. This increased recruitment of spine neurosurgeons may represent the awareness of the growing complexity of the subspecialty or an enlarging market share for the field of neurosurgery.[3,4,9]

Recruitment for academic positions showed modest increases, despite the unsettled climate of healthcare delivery in the university setting. In academic neurosurgery, in which compartmentalization into subspecialties occurs more frequently than in private practice, we found a (nonsignificant) shift in the demand from generalists toward subspecialists (Fig. 2). By 1997 to 1998, 81\% of academic advertised positions sought experience in neurosurgical subspecialties. Advertisements for subspecialists in spine and pediatric neurosurgery were most common (Table 1).

The number of private practice recruitment advertisements more than doubled during the study period and peaked during 1997-1998, suggesting recovery from a flat or possibly declining period of recruitment from 1989 to 1995. In private practice, generalist recruitment advertisements dominated subspecialist advertisements throughout the entire study period. However, there was a shift toward subspecialization during the last 3 recruitment years $(16.3 \pm 3.4 \%)$ compared with the preceding decade $(7.8 \pm 2 \%)$. The greater emphasis on subspecialty recruitment in both academic and private practice spheres indicates that fellowship training may confer an advantage in the job market. This may sharpen competition for fellowship training in the future.

Concerning the size of the practice venue, group practice demonstrated greater recruitment in private practice. The increase in the number of advertisements in private practice was due primarily to the increase in the number of advertisements seeking to add a neurosurgeon to an existing practice of two or more neurosurgeons. In this aspect our data support the findings of the comprehensive practice survey[12] that group practice has shown the greatest growth in participation, compared with other practice sizes.

Although there are limitations in using a review of advertisements for available positions to estimate workforce demand, advertisements for physicians have been used previously as a quantifiable and objective index of workforce trends over an extended period of time.[15] Economic changes based on job availability have been analyzed for more than 20 years by using newspaper help-wanted advertisements in the Conference Board help-wanted index.[1,14] Recognizing that short-term variations, during which acute periods of surplus or scarcity can occur, may conceal long-term trends, we used recruitment advertisements from alternating years to measure workforce dynamics over an extended period of time, 13 years. However, in response to concerns that the need for neurosurgeons has sharply declined, we included data from each of the past 3 recruitment years to investigate evidence of recent changes in workforce recruitment dynamics. 
To consider these data as indicative of the trend in neurosurgical workforce, we assume that the number of advertisements reflects a constant fraction of the total demand for new neurosurgeons. However, the extent to which other methods of recruitment have increased or decreased during the past 13 years may affect submission of advertisements to journals. Because recruitment of resident graduates is also conducted by recruitment firms, mailings, and by word of mouth, changes in the extent to which these alternatives are used in lieu of advertisements may have led us to conclude falsely that workforce demands have been constant during the study period. However, we observed an annual average of 96 advertised positions during the course of the study, which parallels the number of neurosurgery resident graduates per year (approximately 128/year), suggesting a satisfactory representation of neurosurgical workforce demand by using recruitment advertisements.

Seifer and coworkers[15] showed a steep decline in the ratio of specialist positions compared with general medicine positions from 1990 to 1995 . Generalizing from their results, they suggested that a significant downsizing and decrease in workforce demand had occurred for all medical specialists. However, their data concerning specialty practice was obtained from three journals, only one of which infrequently contains neurosurgical advertisements and only one of which represented a surgical specialty (orthopedic surgery). In contrast, using a similar methodology and applying it to neurosurgery journals, our more recent data demonstrate no decrease in the overall demand for neurosurgeons and an increase in the demand for subspecialty expertise.

Alberstone, et al.,[2] analyzed neurosurgical advertisements published in Neurosurgery and the Journal of Neurosurgery for every 3rd year from 1984 to 1995. They reported a decrease of $13 \%$ in the number of advertisements from 1990 to 1995. Similar to Alberstone, et al., we found a decreased number of advertisements published during the recruitment year 1995-1996, compared with the previous study year. However, after including more recent data, our results indicate that the 1995 data may represent a transient slump superimposed on a considerably more optimistic job market for neurosurgeons.

Various sophisticated approaches, such as needs-based and/or demand-based analysis, as well as population-based benchmarking, have been used for strategic planning in the quest for a balance between physician supply and the need for general and specialty care.[7,10] Estimating a change in workforce demand requires careful monitoring of information to assess reliably job availability for clinically active physicians. One such source, medical journal recruitment advertisements, provides a publicly accessible window into workforce changes that presently indicates a continued demand for neurosurgeons and an increasing demand for neurosurgical subspecialization.

\section{Acknowledgments}

The authors would like to thank Betsy Cole, Jo Anne Olender, and Trisha Pauley for assistance in the preparation of this manuscript.

\section{References}

1. Abraham KG, Wachter M: Help-wanted advertising, job vacancies, and unemployment; comments and discussion, in Brainard WC, Perry GL (eds): Brooking Papers on Economic Activity. Washington, DC: Brookings Institute, 1987, pp 207-248

2. Alberstone CD, Benzel EC, Garcia D: Neurosurgery in the marketplace. AANS Bull Spring:13, 1998 
3. Ausman JI: Have neurosurgeons lost their chance to operate on patients with spine problems, vascular disease, and peripheral nerve problems? Surg Neurol 43:424-427, 1995 (Editorial)

4. Benzel EC: Redefining neurosurgery to meet new market demands. AANS Bull Spring:15, 1998 (Letter)

5. Council on Graduate Medical Education: Improving Access to Health Care Through Physician Workforce Reform: Directions for the 21st Century. Washington, DC: United States Department of Health and Human Services, Vol 1, 1992

6. Flexner A: Medical Education in the United States and Canada: A Report to the Carnegie Foundation for the Advancement of Teaching. New York: Carnegie Foundation for the Advancement of Teaching, 1910

7. Goodman DC, Fisher ES, Bubolz TA, et al: Benchmarking the US physician workforce. An alternative to needs-based or demand-based planning. JAMA 276:1811-1817, 1996

8. Kennedy EM: National health security. Tufts Health Sci Rev 2:8-11, 1971

9. Koenig GH: Have neurosurgeons lost their chance to operate on spine problems? Surg Neurol 46:103, 1996 (Editorial)

10. Meyer GS, Jacoby I, Krakauer H, et al: Gastroenterology workforce modeling. JAMA 276:689-694, 1996

11. Mosberg WH Jr: Medical manpower needs at home and abroad. Neurosurgery 30:639-649, 1992

12. Pevehouse BC, the Gary Siegel Organization: Comprehensive Neurosurgery Practice Survey. Park Ridge, Ill: American Association of Neurological Surgeons and the Congress of Neurological Surgeons, 1995

13. Popp AJ: The neurosurgical workforce: market effects, public policy, and professional constraints, in Bean JR (ed): Neurosurgery in Transition. The Socioeconomic Transformation of Neurological Surgery. Concepts in Neurosurgery, Vol. 9. Baltimore: Williams \& Wilkins, 1998, pp 112-132

14. Preston NL: The Help-Wanted Index: Technical Description and Behavioral Trends: A Research Report from the Conference Board's Division on Economic Research. New York: Conference Board, 1977

15. Seifer SD, Troupin B, Rubenfeld GD: Changes in marketplace demand for physicians. A study of medical journal recruitment advertisements. JAMA 276:695-699, 1996

16. Tarlov RA: HMO enrollment growth and physicians: the third compartment. Health Aff 5:23-35, 1986

17. Watts C: Neurosurgical manpower requirements for 1990: an estimate of the Graduate Medical Education National Advisory Committee. Neurosurgery 8:277-279, 1981

18. Wennberg JE, Goodman DC, Nease RF, et al: Finding equilibrium in U.S. physician supply. Health Aff 12:89-103, 1993

19. Wiener JP: Forecasting the effects of health reform on US physician workforce requirement. 
Evidence from HMO staffing patterns. JAMA 272:222-230, 1994

20. Zuidema GD: The SOSSUS report and its impact on neurosurgery. J Neurosurg 46:135-144, 1977

Manuscript received November 12, 1998.

Accepted in final form December 8, 1998.

The data contained in this article were presented in part at the Congress of Neurological Surgeons Annual Meeting, September 1997.

Address reprint requests to: A. John Popp, M.D., Division of Neurosurgery, Albany Medical Center, Albany, New York 12208. email: jpopp@ccgateway.amc.edu. 